\title{
APPLICATION OF PULSE ATOMIZING JET IN ELECTRIC ARC METALLIZING
}

\author{
V.A. ROYANOV ${ }^{1}$ and V.I. BOBIKOV ${ }^{2}$ \\ ${ }^{1}$ Priasovsky State Technical University \\ 7 Universitetskaya Str., 87500, Mariupol, Donetsk region, Ukraine. E-mail: royanov@pstu.ed \\ ${ }^{2}$ Company «Azovobshchemash» \\ 1 Mashinostroitelej Str., 87535, Mariupol, Donetsk region, Ukraine. E-mail: voffka-008@mail.ru
}

\begin{abstract}
The paper presents the results of investigation of pulse atomizing air jet application in electric arc metallizing. To ensure the pulsed mode, the respective device was developed allowing control of outflowing of a jet with frequency within $0-130 \mathrm{~Hz}$. Oscillograms of variation of dynamic pressure are given. Dependence of pulse atomizing air jet on frequency of closing the spray gun nozzle channel is shown. Coating microstructures are given. Influence of pulsation frequency on composition of coatings spray-deposited with PP-MM-2 wire is shown. 15 Ref., 6 Figures.
\end{abstract}

Keywords: arc metallizing, pulsed mode, atomizing air jet, spray gun nozzle channel, coating microstructure, outflow, stationary discontinuity, jet dynamic pressure

Electric arc metallizing is one of the methods of deposition of thermal spray coatings and features high efficiency, and quite cost-effective and readily realized process of coating spray-deposition. It is known that during metallizing process liquid metal of molten electrode tips is directed by the atomizing air jet onto the item [1,2]. Quality of produced coatings depends on the quantity of oxygen, dissolved in particle metal. Data given in [3-8] show that during metallizing an intensive chemical interaction of atomizing air jet with the material being sprayed takes place, leading to a considerable burning out of alloying elements. Oxidation intensity increases with increase of parameters, such as compressed air pressure and distance from apparatus nozzle to item being coated, that has a negative influence on coating mechanical properties. Degree of oxidizing reaction depends on spray material oxidation resistance, particle dispersity, component affinity to oxygen. Quantitative evaluation of the de- gree of oxidation of the components of spray electrode material is given in [5-7].

In order to lower the oxidizing action of atomizing jet on liquid metal of consumable electrode tips, it is proposed to apply a pulse atomizing air jet. To solve the defined task, it was necessary to develop an appropriate device.

Earlier publications [9-12] gave examples of improvement of arc spray gun design by application of inserts and devices to provide pulsation of atomizing air jet. They, however, turned out to be unacceptable in view of their complicated design and inertia in operation.

The Chair of Welding Production Equipment and Technology of Priazovsky State Technical University developed the method of electric arc metallizing with application of pulse atomizing air jet. Investigations were conducted with stationary arc spray gun EM-17 with a device providing pulsed mode of atomizing jet outflow.

In terms of design, the pulse device (further on referred to as pulser) is a cylindrical case with input and output nipples for compressed air input and output, inside which a shaft with an opening

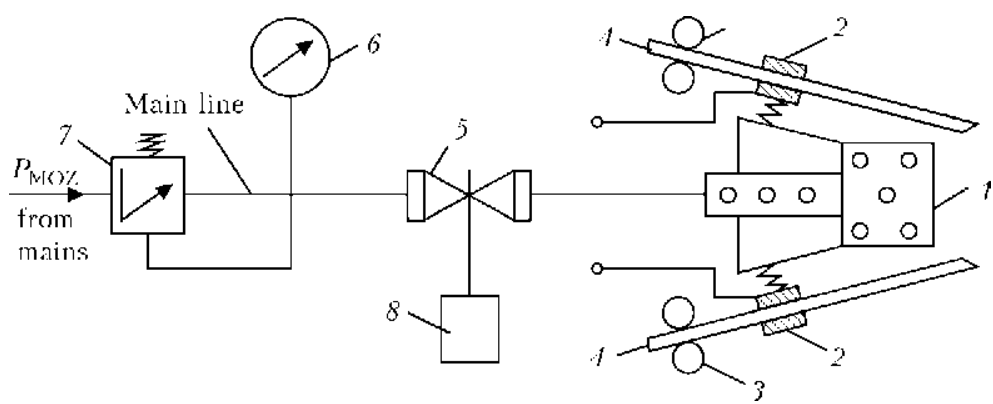

Figure 1. Schematic of head for pulse atomization: 1 - atomizing nozzle; 2 - current conduits; $3-$ rollers; $4-$ electrode material; 5 - pulser; 6 - pressure gage; 7 - pressure reducer; 8 - electric motor 
and rotation capability is mounted. The device is mounted coaxially with spray gun nozzle channel before the spray nozzle. Rotation of the shaft with an opening leads to periodical closure of compressed air feeding along the channel of spray gun nozzle to spray nozzle, thus providing the pulsed mode of outflow. Pulser provided pulsed mode of spray jet outflow in the range of 0 $130 \mathrm{~Hz}$. Schematic of the developed pulse spray head is shown in Figure 1.

During development of the device, effectiveness of jet dynamic pressure and pulse shape depending on spray gun channel flow section was studied. Experimental measurements of pulse shape and dynamic pressure, depending on frequency, were performed by the method of atomizing jet impact on a metal plate, on which the strain gauge was mounted (Figure 2). Signals from the strain gauge were recorded by an oscillograph.

The given oscillograms show that the atomizing jet is of a pulsed nature with time intervals. As shown by investigations, application of different flow sections of nozzle channel allows changing also the nature of rise of the pulse proper. So, at application of a round section the pulse has a smoothly rising shape (Figure 2, $a$, $b)$. A common feature of the sinusoidal and rectangular shape of closure (Figure 2,c, $d$ ) is presence of a pause in atomizing, required for liquid metal formation at electrode tip. Furtheron, investigations with rectangular pulse shape were performed.

Investigation of dependence of the nature of pulse atomizing air jet on nozzle flow channel was performed by the shadow method. Gas spectrograph of the gas jet without pulsing (Figure 3, $a$ ) is characterized by a nonstationary spatially non-uniform gas formation [13]. All the jet areas are in oscillatory motion relative to the geometrical axis of the nozzle, from which it flows. A
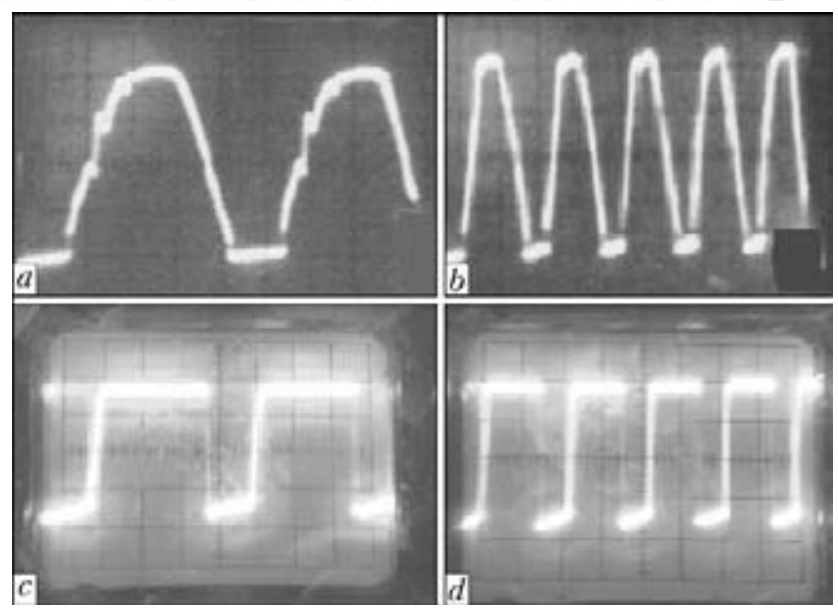

Figure 2. Change of jet dynamic pressure depending on applied flow section of the nozzle with pulsation frequency of $30(a), 65(b), 40(c)$ and $75(d) \mathrm{Hz}$

barrel-shaped wave structure of the initial and transition areas is observed with saw-like pressure distribution along the jet axis. Rarefaction flow in the form of a concentrated wave forms at the nozzle edge.

Atomizing jet with air flow pulsation (Figure $3, b-d$ ) also is a non-uniform gas formation, having a different form, however.

So, at pulse frequency of $25 \mathrm{~Hz}$ (see Figure 3, b) the gas jet, when leaving the nozzle, forms a centered cone-shaped zone limited by rarefaction waves. At frequencies of 56 and $85 \mathrm{~Hz}$ (Figure 3, $c, d)$ all the jet areas make oscillatory motions. Rarefaction waves, which are accompanied by shock waves, barrel-shaped wave structure of the initial and transition areas with saw-like pressure distribution along the jet axis, are observed. An area of stationary discontinuity of the gas jet is found between the waves. At the frequency of $85 \mathrm{~Hz}$ increase of the number of stationary discontinuity areas with pressure gradients is observed.

Coating properties were studied on samples made by electric arc metallizing at different fre-
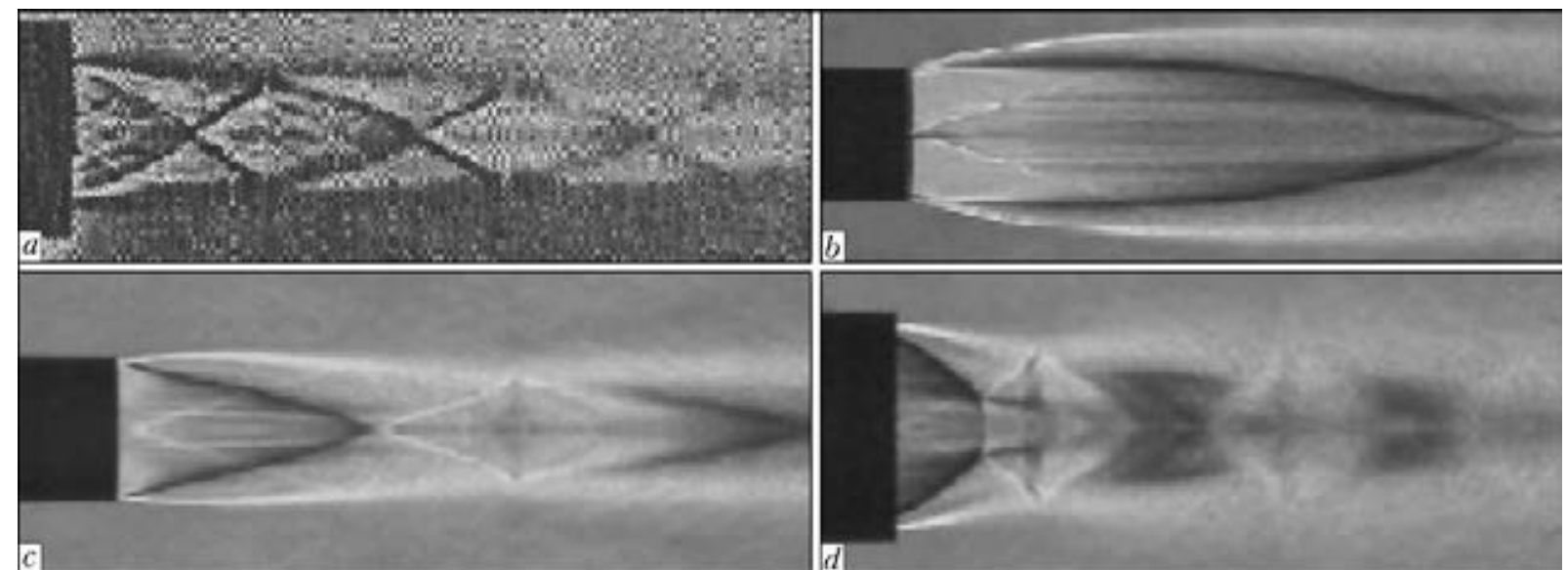

Figure 3. Gas spectrographs of gas jets without pulsation $(a)$ and with pulsation frequency of $25(b), 56(c)$ and $85(d) \mathrm{Hz}$ 

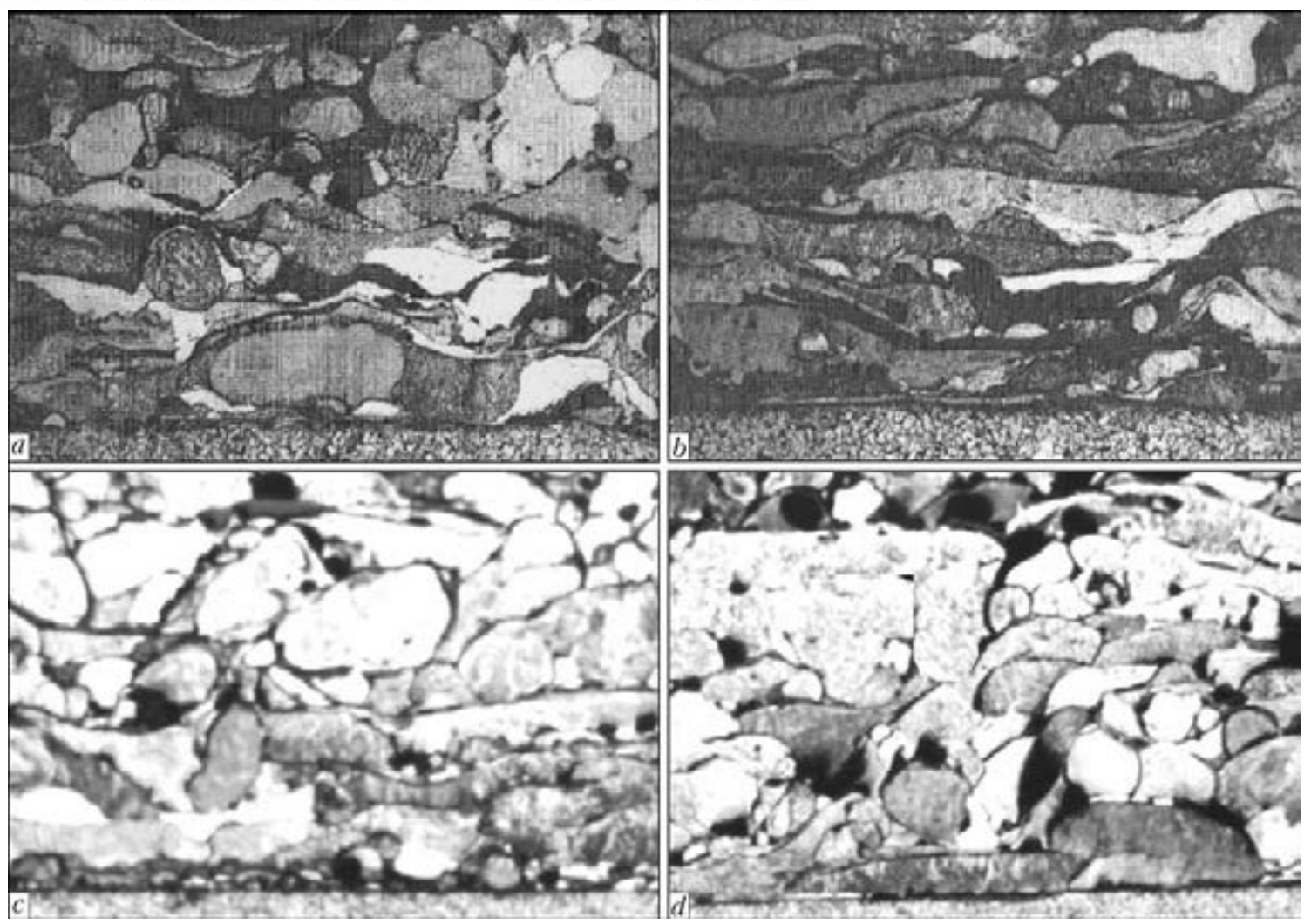

Figure 4. Microstructure $(\times 75)$ of coatings produced without pulsation $(a)$ and with jet pulsation frequency of $43(b)$, $65(c)$ and $105(d) \mathrm{Hz}$

quencies of atomizing air jet. 09G2S steel in the form of plates of $75 \times 35 \times 5 \mathrm{~mm}$ size was used as base material. Before metallizing the samples were degreased with benzene and subjected to sandblasting by corundum with subsequent cleaning by compressed air (to remove dust). Metallizing was conducted using arc spray gun EM-17 with the developed device in the following modes: at pressure $P=0.55 \mathrm{MPa}$, current $I=210-230 \mathrm{~A}$, voltage $U=30-32 \mathrm{~V}$, and wire feed rate $v=4.8-5.4 \mathrm{~m} / \mathrm{min}$. Nozzle of diameter $d=7 \cdot 10^{-3} \mathrm{~m}^{2}$ was used for atomizing. Distance to sprayed sample was $120 \mathrm{~mm}$. Power was supplied to the arc from VDU-506 source.

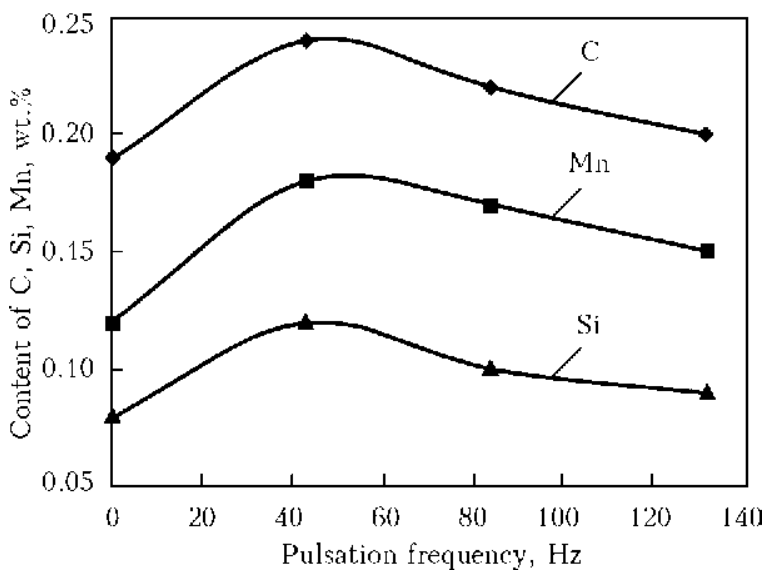

Figure 5. Influence of pulse frequency on $\mathrm{C}, \mathrm{Mn}$ and $\mathrm{Si}$ content in the coating at metallizing with PP-MM-2 wire
Microstructure of coatings, produced at different frequency of pulse atomizing air jet using flux-cored wire PP-MM-2 [14] is shown in $\mathrm{Fi}^{-}$ gure 4.

Microstructure, thickness and porosity of coatings were studied in electron optical microscope Zeiss-200M. Structure of produced coatings corresponds to the data given in $[5,7,8$, 15], where the coating consists of individual deformed particles located in layers. Boundaries from oxide films are observed between the particles and layers, and there is a boundary layer between the base and coating.

Without pulsation coating structure is nonuniform, with a large quantity of particles of different shape (see Figure 4, $a$ ). Particles of spherical shape, not broken up by air pressure into finer ones, are noted. Most of the particles have an elongated deformed shape. Presence of oxide films is noted. At application of a pulse jet the coatings have a more uniform microstructure. Quantity of particles of different size decreases. At pulsation frequency of $43 \mathrm{~Hz}$, coating structure is uniform across the entire thickness that is indicative of process stability. All the particles are subjected to considerable plastic deformation (see Figure $4, b$ ). The transition zone has oxide films, but to a smaller degree, compared to structure of coating made without pulsation. Average particle size is within $100-450 \mu \mathrm{m}$. 

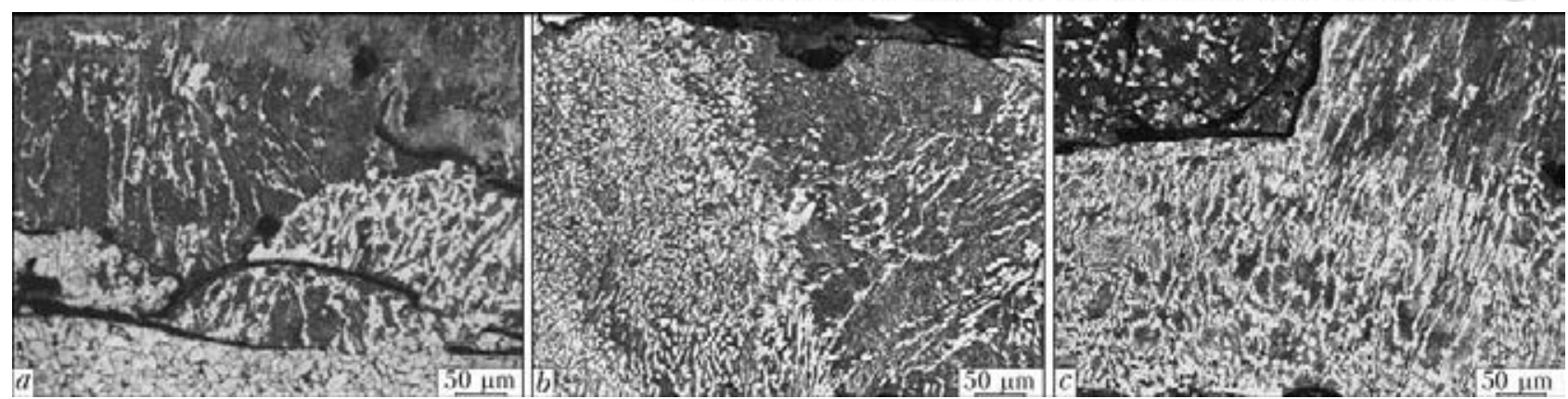

Figure 6. Microstructure of particles, in which oxide film breaking up occurred on the boundary of particles with base $(a, c)$ and between particles $(b)$

At $65 \mathrm{~Hz}$ frequency, an increase of the number of small-sized particles is noted alongside coarse ones (see Figure 4, $c$ ). Average particle size varies within $50-350 \mu \mathrm{m}$. This is attributable to the fact that the interval in repetition of atomizing jet pulses is shorter, compared to particles produced at the frequency of $43 \mathrm{~Hz}$. The rate of electrode melting and formation of liquid metal at the tip has longer time than the time interval in repetition of atomizing air jet pulses at this frequency, that increases the force of liquid metal throwing off electrode tips by the atomizing flow force. At $105 \mathrm{~Hz}$ frequency no significant change in particle sizes was noted. Presence of an interval in atomizing jet pulse repetition is of little importance, compared to the time required for liquid metal formation at consumable electrode tips. The force of impact of atomizing flow on liquid metal becomes practically constant.

During research performance variable data on composition of coatings sprayed on samples with application of various frequencies of atomizing pulses were obtained (Figure 5). Difference in chemical element content is attributable to different degrees of oxidizing medium impact on the material being sprayed.

Microstructures of particles, in which oxide film breaking up on the boundaries took place, are an illustration of lowering of oxidizing impact on atomized material (Figure 6).

A test sample was developed of a head for metallizing in the pulsed mode, mounted on a lathe, in order to restore the seats of metallurgical equipment parts in mechanical shop of «Azovstal» Works.

\section{Conclusions}

1. A device was developed providing pulsed atomizing mode with rectangular pulses in frequency range of $0-132 \mathrm{~Hz}$.
2. Application of pulse atomization allows stabilizing coating composition.

3. At metallizing with PP-MM-2 wire optimum pulse frequency is equal to $35-60 \mathrm{~Hz}$.

1. Korobov, Yu.S. (2004) Estimation of forces affecting spray metal in electric arc metallizing. The Paton Welding J., 7, 21-25.

2. Royanov, V.A. (1990) Melting of electrodes in electric arc metallizing. Svarochn. Proizvodstvo, 2, 35-37.

3. Borisov, Yu.S., Vigilanskaya, N.V., Demianov, I.A. et al. (2013) Investigation of dispersion of dissimilar wire materials during electric arc metallizing. The Paton Welding J., 2, 24-30.

4. Korobov, Yu.S., Boronenkov, V.N. (2003) Kinetics of interaction of sprayed metal with oxygen in electric arc metallizing. Svarochn. Proizvodstvo, 7, 3036 .

5. Hasui, A. (1975) Technique of metallizing. Moscow: Mashinostroenie

6. Konstantinov, V.M., Gubanov, A.S. (2007) Effect of alloying elements of steel wire on structure and properties of coatings in electric arc metallizing. Svarochn. Proizvodstvo, 5, 13-18.

7. Boronenkov, V.N., Korobov, Yu.S. (2012) Principles of electric arc metallizing. Physical-chemical principles. Ekaterinburg: UralSU.

8. Katz, N.V. (1966) Spray coating. Moscow: Mashinostroenie.

9. Ter-Danielian, B.I., Krasnichenko, L.V. (1983) New spray head of arc spray gun. Svarochn. Proizvodstvo, 12, 30-32.

10. Buryakin, A.V. (2000) Stationary arc spray gun EM19. Ibid., 9, 35-36.

11. Royanov, V.A., Mosienko, G.A., Semyonov, V.P. et al. Atomizing spray head. USSR author's cert. 1787049. Int. Cl. B 05 B $7 / 22$. Fil. 22.11.89. Publ. 07.01.93.

12. Borisov, Yu.S., Ilienko, A.G., Astakhov, E.A. et al. Device for arc metallizing. USSR author's cert. 1727923. Int. Cl. B 05 B $7 / 22$. Fil. 26.06.89. Publ. 23.04.92.

13. Ginzburg, A.P. (1968) Aerogasdynamics. Moscow: Vysshaya Shkola.

14. Royanov, V.A., Tsygankov, S.A., Bogoslovsky, A.S. (1990) Flux-cored wire for deposition of wear-resistant coatings by arc spaying. In: Transact. of TsNIIT-MASh, 25-26.

15. Kudinov, V.V., Bobrov, G.V. (1992) Metallizing of coatings. Theory, technology and equipment: Manual for inst. of higher education. Moscow: Metallurgiya.

Received 05.05.2014 